\title{
Prevalence of Osteoporosis and Its Risk Factors in Men with COPD in Qazvin
}

\author{
Mahnaz Abbasi, ${ }^{1}$ Mohammadali Zohal, ${ }^{2}$ Banafsheh Atapour, ${ }^{3}$ and Zohreh Yazdi ${ }^{4}$ \\ ${ }^{1}$ Rheumatology, Metabolic Diseases Research Center, Qazvin University of Medical Sciences, Qazvin, Iran \\ ${ }^{2}$ Pulmonary Diseases, Metabolic Diseases Research Center, Qazvin University of Medical Sciences, Qazvin, Iran \\ ${ }^{3}$ Metabolic Diseases Research Center, Qazvin University of Medical Sciences, Qazvin, Iran \\ ${ }^{4}$ Occupational Medicine, Social Determinants of Health Research Center, Qazvin University of Medical Sciences, Qazvin, Iran
}

Correspondence should be addressed to Mohammadali Zohal; mzohal@qums.ac.ir

Received 29 April 2016; Revised 24 August 2016; Accepted 14 September 2016

Academic Editor: Mariano Bizzarri

Copyright (C) 2016 Mahnaz Abbasi et al. This is an open access article distributed under the Creative Commons Attribution License, which permits unrestricted use, distribution, and reproduction in any medium, provided the original work is properly cited.

Introduction. Chronic obstructive pulmonary disease (COPD) is a major cause of morbidity and mortality worldwide. Proper diagnosis of osteoporosis as a systemic adverse effect of COPD is of significant importance. The present study aimed at evaluating the prevalence of osteoporosis and its risk factors in men suffering from COPD in Qazvin (2014). Methods. This descriptiveanalytical study was conducted on 90 patients with COPD using random sampling. Anthropometric data and results from physical examination were collected. Pulmonary function test and bone mineral densitometry were done for all participants as well. Results. The prevalence of osteopenia and osteoporosis in COPD patients was 31.5 and 52.8 percent, respectively. Bone mineral density (BMD) at the femoral neck was associated significantly with body mass index (BMI), increased severity of COPD, and use of oral corticosteroid $(P<0.05)$. Conclusion. The results showed that patients' BMI and severity of COPD are two valuable risk factors for osteoporosis screening in COPD patients.

\section{Introduction}

Chronic obstructive pulmonary disease (COPD) is a progressive lung disease with prevalence rate of 5-13 percent $[1,2]$. COPD is characterized by inflammation in the lung parenchyma and airways and irreversible obstruction in airflow. Patients suffering from COPD present with shortness of breath, dyspnea on exertion, cough, and sputum production [3]. It is a multisystem disorder that affects many organs such as bones causing osteopenia and osteoporosis $[4,5]$.

Osteopenia is a condition in which bone mineral density is reduced. Likewise, osteoporosis is a more severe condition, where decreased bone density increases the risk of fracture. The most common sites of fracture are wrist, spine, ribs, and hip. These fractures can result in pain, disability, reduced mobility, and other serious injuries [6].

Recent evidences suggest that osteoporosis in COPD patients is debilitating. Osteoporosis can cause multiple vertebral fractures in spine which result in a loss of at least
$15-20 \%$ of its height. These fractures often result in patients' height loss, chronic pain, and kyphosis which ultimately damage respiratory function. The complications can lead to death if they are left untreated $[7,8]$.

Researchers are investigating further to clarify the relationship between osteoporosis and COPD. Most researchers, however, believe that the two diseases have a number of risk factors in common including smoking, older age, low level of vitamin D, long-term treatment with corticosteroids, excessive weight loss, and low body mass index in patients. Moreover, 22 to 69 percent of men with COPD may develop hypogonadism that has been associated with other systemic manifestations including osteoporosis and depression $[4,9$, $10]$.

Since osteoporosis is a chronic disease similar to COPD and tends to deteriorate with age, it is crucial to pay more attention to its risk factors so as to enable its prevention, early diagnosis, and treatment. Thus, estimating the prevalence of risk factors for osteoporosis in patients with COPD is 
important. For example, it is possible to use bisphosphonates for prophylaxis and treatment of osteoporosis, if corticosteroids are recognized as the main culprit in COPD patients $[11,12]$. Proper protective effect of bisphosphonates has been reported in glucocorticoid-induced osteoporosis in previous studies [11-13].

Since most COPD patients are old men with risk factors for osteoporosis, the present study aimed to evaluate the prevalence of osteoporosis and detect its risk factors in men with COPD in Qazvin (2014).

\section{Methods}

This cross-sectional study was performed in lung clinic of Bouali Hospital in Qazvin in 2014. Ninety men with COPD aged from 60 to 86 years were enrolled. The study was approved by the ethics committee of Qazvin University of Medical Sciences (QUMS). Inclusion criteria were diagnosis of COPD by pulmonologist and obtaining informed consent from patients, whereas exclusion criteria included history of asthma or any chronic pulmonary disorders except COPD, history of bone disease, and patients who had been treated for osteoporosis or used diuretics. In addition, patients with chronic diseases affecting the bone mineral density (e.g., hyperthyroidism) or patients with a history of thoracic surgery and malignancy were excluded. Diagnosis of COPD in the patients was considered according to criteria provided by American Thoracic Society (ATS) and European Respiratory Society (ERS) [14].

For this purpose, pulmonologist used the patients' medical records, current symptoms, and the results of pulmonary function test. Lung function was assessed by trained technicians (SPM300 spirometer). The forced expiratory volume 1 (FEV1) and forced vital capacity (FVC) were measured by spirometer, and the FEV1/FVC ratio was calculated. COPD was diagnosed for the patients through spirometry, where postbronchodilatory FEV1/FVC was lower than $70 \%$.

Using FEV1, according to GOLD guideline, the COPD patients were then classified into four groups of severity [15].

Having calculated the body mass index (BMI) by dividing weight (in kilograms) by the square of the weight, the patients were categorized as underweight $\left(\mathrm{BMI}<17 \mathrm{~kg} / \mathrm{m}^{2}\right)$, normal weight (17-25 kg/m $\left.{ }^{2}\right)$, overweight $\left(25.1-30 \mathrm{~kg} / \mathrm{m}^{2}\right)$, and obese $\left(>30 \mathrm{~kg} / \mathrm{m}^{2}\right)$ [16].

The bone mineral density was measured by using dualenergy X-ray absorptiometry at lumbar spine and femoral neck (Hologic QDR 2000, Bedford, MA, USA, model). The results of $\mathrm{BMD}$ were categorized according to the $\mathrm{WHO}$ criteria. Therefore, subjects with spine or femur neck $T$-score of -2.5 or below were considered as having osteoporosis. Subjects with $T$-score between -1 and -2.5 and more than -1 were considered as having osteopenia and normal people, respectively [17].

Data were presented using frequency and percentage for categorical variables. Chi-square test was used to compare qualitative variables. All statistical analyses were performed using SPSS software version 19 and $P$ values less than 0.05 were considered statistically significant.

\section{Results}

A total of 90 patients with COPD aged from 60 to 86 years (mean age: $69 \pm 6$ ) participated in this study. The majority of patients (61.8\%) were between 60 and 69 years, and $30.3 \%$ and $7.9 \%$ of patients were between 70 and 79 years and between 80 and 89 years, respectively. The mean body mass index (BMI) was $22.2 \pm 4.17 \mathrm{~kg} / \mathrm{m}^{2}$, and $44.9 \%$ of patients had normal BMI.

Based on GOLD criteria, 14 (15.7\%) patients had GOLD II, $27(30.3 \%)$ patients had GOLD III, and 31 (34.8\%) patients had GOLD IV. The mean lumbar spine and neck of femur BMD of the patients were $0.85 \pm 0.15$ and $0.7 \pm 0.12$, respectively.

According to WHO criteria, 47 patients (52.8\%) had osteoporosis. Results for relationship between variables and bone mineral density in the lumbar spine and neck of femur are shown in Table 1.

As shown in the table, only BMI and severity of COPD were significantly associated with osteoporosis. This relationship was not found in other risk factors. The statistically significant relationship was observed only between severity of COPD and osteoporosis in neck of femur $(P=0.042)$. As seen in Figure 1, with increasing the severity of COPD in patients, severity of bone loss (osteoporosis) increased significantly.

Figure 2 shows the relationship between patients' BMI and osteoporosis based on $T$-score of femoral neck. As illustrated in Figure 2, reduction in patients' BMI leads to significant increase in osteoporosis.

Statistical analyses did not show any significant relationship between oral corticosteroid use and osteoporosis based on lumbar spine $T$-score. Other results, however, showed that there was a significant correlation between dose of oral corticosteroid and patients' osteoporosis based on femoral neck $T$-score $(r=0.26 ; P$ value $=0.015)$.

\section{Discussion}

In this study, the prevalence of osteopenia and osteoporosis in COPD patients was $31.5 \%$ and $52.8 \%$, respectively. In a study conducted by Abu-Bakr and his colleagues, the prevalence of osteopenia and osteoporosis was observed in 50 and 30 percent of COPD patients [8]. The results were consistent with those of another study conducted by Mansour and his colleagues. They reported the prevalence of osteoporosis and osteopenia in COPD patients as a range of $9-69 \%$ and a range of $27-76 \%$, respectively. Their explanation for the differences observed in the studies was using different diagnostic methods, different study population, and different severity in the underlying respiratory disease $[8,18]$.

In the present study, severity of osteoporosis according to femoral neck $T$-score increased with the increase of the severity of COPD. In other words, reduction of FEV1 in subjects was associated with low levels of bone mineral density. Nuti and his colleagues also found similar results and showed that bone mineral density in COPD patients was low and decreased with increasing disease severity [19]. Nevertheless, the relationship between lung function parameters and osteoporosis is complex and ambiguous. Cellular 
TABLE 1: Frequency of different risk factors of osteoporosis in COPD patients.

\begin{tabular}{|c|c|c|c|c|c|c|c|c|}
\hline \multirow{2}{*}{ Variable } & \multicolumn{3}{|c|}{ Spine } & \multirow{2}{*}{$P$ value } & \multicolumn{3}{|c|}{ Femur } & \multirow{2}{*}{$P$ value } \\
\hline & Normal & Osteopenia & Osteoporosis & & Normal & Osteopenia & Osteoporosis & \\
\hline \multicolumn{9}{|l|}{ Age (year) } \\
\hline 60-69 & $10(11.2 \%)$ & $19(21.3 \%)$ & $26(29.2 \%)$ & \multirow{3}{*}{0.49} & $13(14.6 \%)$ & $28(31.5 \%)$ & $14(15.7 \%)$ & \multirow{3}{*}{0.52} \\
\hline $70-79$ & $8(9 \%)$ & $8(9 \%)$ & $11(12.4 \%)$ & & $7(7.9 \%)$ & $9(10.1 \%)$ & $11(12.4 \%)$ & \\
\hline $80-89$ & $0(0 \%)$ & $3(3.4 \%)$ & $4(4.5 \%)$ & & $1(1.1 \%)$ & $3(3.4 \%)$ & $3(3.4 \%)$ & \\
\hline \multicolumn{9}{|l|}{ Smoking (pack/year) } \\
\hline$<20$ & $2(2.2 \%)$ & $8(9 \%)$ & $8(9 \%)$ & \multirow{3}{*}{0.76} & $5(5.6 \%)$ & $9(10.1 \%)$ & $4(4.5 \%)$ & \multirow{3}{*}{0.82} \\
\hline $21-40$ & $7(7.9 \%)$ & $10(11.2 \%)$ & $16(18 \%)$ & & $7(7.9 \%)$ & $16(18 \%)$ & $10(11.2 \%)$ & \\
\hline$>40$ & $9(10.1 \%)$ & $12(13.5 \%)$ & $17(19.1 \%)$ & & $9(10.1 \%)$ & $15(16.9 \%)$ & $14(15.7 \%)$ & \\
\hline \multicolumn{9}{|l|}{ Severity of COPD } \\
\hline Mild (grade I) & $6(6.7 \%)$ & $4(4.5 \%)$ & $7(7.9 \%)$ & \multirow{4}{*}{0.38} & $5(5.6 \%)$ & $9(10.1 \%)$ & $3(3.4 \%)$ & \multirow{4}{*}{0.042} \\
\hline Moderate (grade II) & $1(1.1 \%)$ & $6(6.7 \%)$ & $7(7.9 \%)$ & & $6(6.7 \%)$ & $3(3.4 \%)$ & $5(5.6 \%)$ & \\
\hline Severe (grade III) & $3(3.4 \%)$ & $11(12.4 \%)$ & $13(14.6 \%)$ & & $3(3.4 \%)$ & $17(19.1 \%)$ & $7(7.9 \%)$ & \\
\hline Very severe (grade IV) & $8(9 \%)$ & $9(10.1 \%)$ & $14(15.7 \%)$ & & $7(7.9 \%)$ & $11(12.4 \%)$ & $13(14.6 \%)$ & \\
\hline \multicolumn{9}{|l|}{ BMI } \\
\hline Low & $19(21.3 \%)$ & $13(14.6 \%)$ & $8(9 \%)$ & \multirow{4}{*}{0.79} & $4(4.5 \%)$ & $21(23.6 \%)$ & $15(16.9 \%)$ & \multirow{4}{*}{0.034} \\
\hline Moderate & $10(11.2 \%)$ & $15(16.9 \%)$ & $5(5.6 \%)$ & & $13(14.6 \%)$ & $11(12.4 \%)$ & $6(6.7 \%)$ & \\
\hline Overweight & $8(9 \%)$ & $3(3.4 \%)$ & $2(2.2 \%)$ & & $2(2.2 \%)$ & $8(9 \%)$ & $3(3.4 \%)$ & \\
\hline Obese & $2(2.2 \%)$ & $4(4.5 \%)$ & $0(0 \%)$ & & $2(2.2 \%)$ & $0(0 \%)$ & $4(4.5 \%)$ & \\
\hline \multicolumn{9}{|l|}{ Corticosteroid } \\
\hline Budesonide & $2(2.2 \%)$ & $4(4.5 \%)$ & $4(4.5 \%)$ & 0.89 & $3(3.4 \%)$ & $5(5.6 \%)$ & $2(2.2 \%)$ & 0.69 \\
\hline Inhaled corticosteroid & $17(19.1 \%)$ & $30(33.7 \%)$ & $40(44.9 \%)$ & 0.45 & $20(22.5 \%)$ & $40(44.9 \%)$ & $27(30.3 \%)$ & 0.42 \\
\hline
\end{tabular}

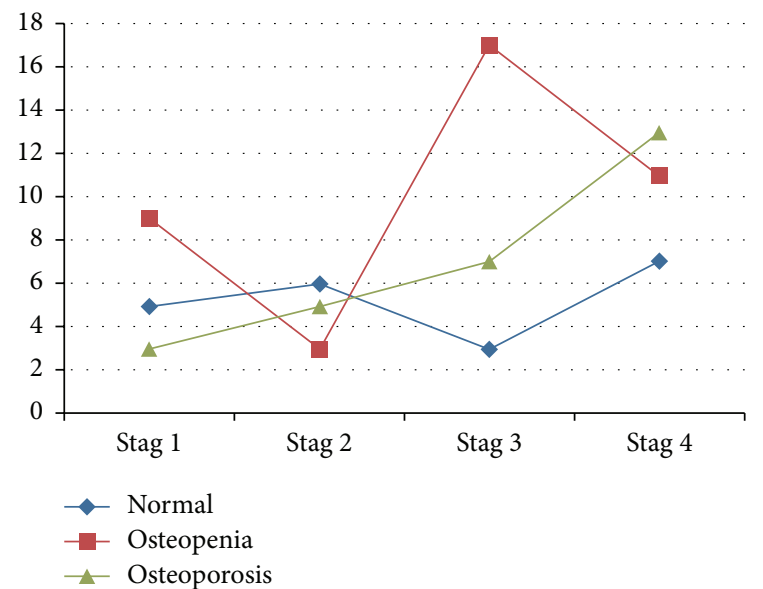

FIGURE 1: Interaction between osteoporosis in the femoral neck and severity of COPD.

microstructural defects in COPD are not well understood as well [20].

An experimental study of transbone biopsy in COPD patients showed that microstructure skeletal disorders (both cancellous and cortical bones) are more in COPD patients compared to control groups [21]. It is very likely that an underlying reason for the disorders is the increased levels of

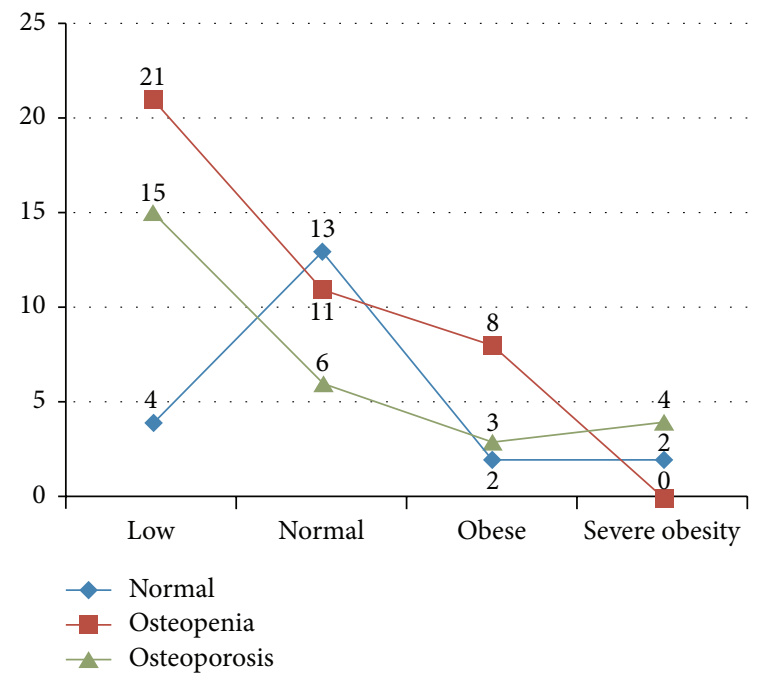

FIGURE 2: Interaction between osteoporosis in the femoral neck and patients' BMI.

cytokines and production of catalytic enzymes. It has been shown that there is a continuous systemic inflammatory state in patients with COPD, which results in the release of inflammatory cytokines such as TNF- $\alpha$, IL-1, and IL-6. On the other hand, production of catalytic enzymes, for example, matrix 
metalloproteinases, increases during the course of COPD. Protein catabolic process and the inflammatory cytokines induce bone resorption and inhibit bone formation [21-24].

The use of corticosteroids in these patients is also considered as another cause of low bone density [22, 25]. This was examined in the present study as well, and a significant relationship was observed between the osteoporosis in femoral neck based on $T$-score and the use of oral corticosteroid. In other words, by increasing the oral corticosteroid use, an increased risk for osteoporosis was observed. Almost all patients were given inhaled corticosteroids in the present study, and no significant relationship was observed between the osteoporosis in lumbar spine based on $T$-score and the use of oral corticosteroid. Similarly, no association was found between inhaled corticosteroid and budesonide use with osteoporosis in both regions. The treatment, however, can be strongly confusing in the interpretation of the results concerning the relevance of COPD and low BMI (at least in this specific sample) as a risk factor for osteoporosis. Israel et al. found a reduced bone density after long-term treatment with triamcinolone [26], but studies on the effects of budesonide and fluticasone did not eventuate in the same results. In the TORCH study carried out by Ferguson et al., no significant effect on bone mineral density for inhaled corticosteroids was found [27]. In another study by Johnell et al., effects of long-term treatment with budesonide on fracture rates and bone mineral density were not found to be clinically significant [28]. In contrast, Nuti et al. showed that both severity of COPD and using inhaled oral glucocorticoid therapy increase the risk of vertebral fractures [19]. Casadp and his colleagues also found that patient's treatment with glucocorticoid and severity of COPD are correlated [29]. In a similar study, Dam et al. found that patients with COPD or asthma using corticosteroid had the lowest amount of BMD, and the risk of osteoporosis in their bones was two times more compared to those without COPD and asthma [30].

In this study, a significant relationship was found between BMI and osteoporosis in femoral neck based on $T$-score, such that a reduction in BMI was shown to be associated with increased severity of osteoporosis. However, no association was observed between BMI and osteoporosis based on Tscore of lumbar spine. Bone mass is directly associated with BMI and patients with a higher BMI have higher BMD [31, 32]. This is partly due to the effect of weight bearing on bones and the higher levels of estrogen in obese people. Aromatization and the conversion of testosterone to estrogen increase in obese people [33]. The effect of BMI on $\mathrm{BMD}$ is reportedly dependent on the bone place in body. Accordingly, hip would be the first to be affected followed by lumbar spine and distal radius, respectively. It has also been suggested that this order may be due to differences in body fat percentage and weight bearing condition in different areas [34]. The mechanism of the relationship between low BMI and osteoporosis is not fully clear in patients with COPD. It is probably due to the increase in inflammatory processes, the decrease in physical activity, and other mechanisms of proteolysis [35-38]. Therefore, osteoporosis is considered as a major problem in men with COPD. It can cause multiple fractures in spines and reduce forced vital capacity (FVC) in COPD patients and, consequently, can exacerbate the adverse effects of COPD in patients. Therefore, identifying and controlling the common risk factors for COPD and osteoporosis are essential in any society [8].

\section{Conclusion}

The results showed that an increase in severity of COPD, using oral corticosteroid, and decrease of BMI are three risk factors for high prevalence of osteoporosis in COPD patients in Qazvin province. Given the importance of osteoporosis in COPD, it is recommended that all COPD patients be screened for osteoporosis so as to prevent serious complications such as but not limited to fractures.

\section{Disclosure}

This study was officially registered as Internal Medicine specialty thesis at the School of Medicine in Qazvin University of Medical Sciences.

\section{Competing Interests}

The authors declare that they have no competing interests.

\section{Acknowledgments}

The authors wish to thank the staff of the Metabolic Disease Research Center, Qazvin University of Medical Sciences, for their help in preparing this paper.

\section{References}

[1] P. Lou, Y. Zhu, P. Chen et al., "Prevalence and correlations with depression, anxiety, and other features in outpatients with chronic obstructive pulmonary disease in China: a crosssectional case control study," BMC Pulmonary Medicine, vol. 12, article 53, 2012.

[2] R. A. Pauwels, A. S. Buist, P. M. A. Calverley, C. R. Jenkins, and S. S. Hurd, "Global strategy for the diagnosis, management, and prevention of chronic obstructive pulmonary disease. NHLBI/WHO Global Initiative for Chronic Obstructive Lung Disease (GOLD) Workshop summary," American Journal of Respiratory and Critical Care Medicine, vol. 163, no. 5, pp. 12561276, 2001.

[3] J. Vestbo, S. S. Hurd, A. G. Agustí et al., "Global strategy for the diagnosis, management, and prevention of chronic obstructive pulmonary disease: GOLD executive summary," American Journal of Respiratory and Critical Care Medicine, vol. 187, no. 4, pp. 347-365, 2013.

[4] L. Graat-Verboom, F. W. J. M. Smeenk, B. E. E. M. van den Borne et al., "Risk factors for osteoporosis in Caucasian patients with moderate chronic obstructive pulmonary disease: a case control study," Bone, vol. 50, no. 6, pp. 1234-1239, 2012.

[5] N. Cielen, K. Maes, and G. Gayan-Ramirez, "Musculoskeletal disorders in chronic obstructive pulmonary disease," BioMed Research International, vol. 2014, Article ID 965764, 17 pages, 2014. 
[6] J. H. M. Driessen, L. Hansen, S. A. Eriksen et al., "The epidemiology of fractures in Denmark in 2011," Osteoporosis International, vol. 27, no. 6, pp. 2017-2025, 2016.

[7] Z. Ciric, I. Stankovic, T. Pejcic, L. Ristic, M. Rancic, and M. Radovic, "Osteoporosis in patients with chronic obstructive pulmonary disease," Medical Archives, vol. 66, no. 6, pp. 385387, 2012.

[8] S. M. Abu-Bakr, M. M. Galal Eldin, M. R. Hafez, S. M. Salem, and H. T. Qandeel, "Assessment of osteoporosis in patients with chronic obstructive pulmonary disease," Egyptian Journal of Chest Diseases and Tuberculosis, vol. 63, no. 3, pp. 597-602, 2014.

[9] C.-W. Lin, Y.-Y. Chen, Y.-J. Chen, C.-Y. Liang, M.-S. Lin, and W. Chen, "Prevalence, risk factors, and health-related quality of life of osteoporosis in patients with COPD at a community hospital in Taiwan," International Journal of Chronic Obstructive Pulmonary Disease, vol. 10, no. 1, pp. 1493-1500, 2015.

[10] S. J. Lee, K. A. Kong, Y. J. Ryu, J. H. Lee, and J. H. Chang, "Latebreaking abstract: risk factors for osteoporosis in patients with COPD: 2008-2010 Korean NHANES," European Respiratory Journal, vol. 44, supplement 58, Article ID P3590, 2014.

[11] S. A. Aljubran, G. J. Whelan, M. C. Glaum, and R. F. Lockey, "Osteoporosis in the at-risk asthmatic," Allergy, vol. 69, no. 11, pp. 1429-1439, 2014.

[12] D. H. Solomon, S. J. Diem, K. Ruppert et al., "Bone mineral density changes among women initiating proton pump inhibitors or $\mathrm{H} 2$ receptor antagonists: a SWAN cohort study," Journal of Bone and Mineral Research, vol. 30, no. 2, pp. 232-239, 2015.

[13] M. Sarkar, R. Bhardwaj, I. Madabhavi, and J. Khatana, "Osteoporosis in chronic obstructive pulmonary disease," Clinical Medicine Insights: Circulatory, Respiratory and Pulmonary Medicine, vol. 9, pp. 5-21, 2015.

[14] B. R. Celli, W. MacNee, A. Agusti et al., "Standards for the diagnosis and treatment of patients with COPD: a summary of the ATS/ERS position paper," European Respiratory Journal, vol. 23, no. 6, pp. 932-934, 2004.

[15] K. F. Rabe, S. Hurd, A. Anzueto et al., "Global strategy for the diagnosis, management, and prevention of chronic obstructive pulmonary disease: GOLD executive summary," American Journal of Respiratory and Critical Care Medicine, vol. 176, no. 6, pp. 532-555, 2007.

[16] E. Anuurad, K. Shiwaku, A. Nogi et al., “The new BMI criteria for asians by the regional office for the western pacific region of WHO are suitable for screening of overweight to prevent metabolic syndrome in elder Japanese workers," Journal of Occupational Health, vol. 45, no. 6, pp. 335-343, 2003.

[17] M. Sahmani, S. Omidian, A. Javadi, M. Sirati Sabet, and M. Abbasi, "Association between the serum levels of zinc, copper and lipid profile with osteoporosis in iranian postmenopausal women," Biotechnology and Health Sciences, vol. 1, no. 1, Article ID e19190, 2014.

[18] O. F. Mansour, R. M. Bakr, R. A. Elwahsh, and A. M. Zanfal, "Osteoporosis in patients with chronic obstructive pulmonary disease," Menoufia Medical Journal, vol. 28, no. 2, pp. 521-524, 2015.

[19] R. Nuti, P. Siviero, S. Maggi et al., "Vertebral fractures in patients with chronic obstructive pulmonary disease: the EOLO study," Osteoporosis International, vol. 20, no. 6, pp. 989-998, 2009.

[20] B. M. Misof, P. Roschger, V. Jorgetti et al., "Subtle changes in bone mineralization density distribution in most severely affected patients with chronic obstructive pulmonary disease," Bone, vol. 79, pp. 1-7, 2015.
[21] C. A. M. Kulak, V. C. Borba, V. Jorgetti et al., "Skeletal microstructural abnormalities in postmenopausal women with chronic obstructive pulmonary disease," Journal of Bone and Mineral Research, vol. 25, no. 9, pp. 1931-1940, 2010.

[22] N. R. Jørgensen and P. Schwarz, "Osteoporosis in chronic obstructive pulmonary disease patients," Current Opinion in Pulmonary Medicine, vol. 14, no. 2, pp. 122-127, 2008.

[23] H. Fujimoto, K. Fujimoto, A. Ueda, and M. Ohata, "Hypoxemia is a risk factor for bone mass loss," Journal of Bone and Mineral Metabolism, vol. 17, no. 3, pp. 211-216, 1999.

[24] C. E. Bolton, A. A. Ionescu, K. M. Shiels et al., "Associated loss of fat-free mass and bone mineral density in chronic obstructive pulmonary disease," American Journal of Respiratory and Critical Care Medicine, vol. 170, no. 12, pp. 1286-1293, 2004.

[25] K. Panday, A. Gona, and M. B. Humphrey, "Medicationinduced osteoporosis: screening and treatment strategies," Therapeutic Advances in Musculoskeletal Disease, vol. 6, no. 5, pp. 185-202, 2014.

[26] E. Israel, T. R. Banerjee, G. M. Fitzmaurice, T. V. Kotlov, K. LaHive, and M. S. LeBoff, "Effects of inhaled glucocorticoids on bone density in premenopausal women," The New England Journal of Medicine, vol. 345, no. 13, pp. 941-947, 2001.

[27] G. T. Ferguson, P. M. A. Calverley, J. A. Anderson et al., "Prevalence and progression of osteoporosis in patients with COPD: results from the towards a revolution in COPD health study," Chest, vol. 136, no. 6, pp. 1456-1465, 2009.

[28] O. Johnell, R. Pauwels, C. G. Löfdahl et al., "Bone mineral density in patients with chronic obstructive pulmonary disease treated with budesonide Turbuhaler ${ }^{\circledR,}$, European Respiratory Journal, vol. 19, no. 6, pp. 1058-1063, 2002.

[29] E. Casado, M. Larrosa, E. Naval et al., "Osteoporosis in men with chronic obstructive pulmonary disease. Utility of phalangeal densitometry (AccuDEXA) as a screening method," Reumatologia Clinica, vol. 1, no. 1, pp. 7-11, 2005.

[30] T.-T. Dam, S. Harrison, H. A. Fink, J. Ramsdell, and E. BarrettConnor, "Bone mineral density and fractures in older men with chronic obstructive pulmonary disease or asthma," Osteoporosis International, vol. 21, no. 8, pp. 1341-1349, 2010.

[31] S. A. Sternberg, R. Levin, S. Dkaidek, S. Edelman, T. Resnick, and J. Menczel, "Frailty and osteoporosis in older women-a prospective study," Osteoporosis International, vol. 25, no. 2, pp. 763-768, 2014.

[32] X. Jiang, L. E. Good, R. Spinka, and P. F. Schnatz, "Osteoporosis screening in postmenopausal women aged 50-64 years: BMI alone compared with current screening tools," Maturitas, vol. 83, pp. 59-64, 2016.

[33] D. M. Biskobing, "Copd and osteoporosis," Chest, vol. 121, no. 2, pp. 609-620, 2002.

[34] P. Ravn, G. Cizza, N. H. Bjarnason et al., "Low body mass index is an important risk factor for low bone mass and increased bone loss in early postmenopausal women. Early Postmenopausal Intervention Cohort (EPIC) study group," Journal of Bone and Mineral Research, vol. 14, no. 9, pp. 1622-1627, 1999.

[35] L. Graat-Verboom, B. E. E. M. van den Borne, F. W. J. M. Smeenk, M. A. Spruit, and E. F. M. Wouters, "Osteoporosis in COPD outpatients based on bone mineral density and vertebral fractures," Journal of Bone and Mineral Research, vol. 26, no. 3, pp. 561-568, 2011.

[36] V. P. Balasubramanian and B. Varkey, "Chronic obstructive pulmonary disease: effects beyond the lungs," Current Opinion in Pulmonary Medicine, vol. 12, no. 2, pp. 106-112, 2006. 
[37] E. F. Wouters, "Local and systemic inflammation in chronic obstructive pulmonary disease," Proceedings of the American Thoracic Society, vol. 2, no. 1, pp. 26-33, 2005.

[38] B. P. Yawn and A. Kaplan, "Co-morbidities in people with COPD: a result of multiple diseases, or multiple manifestations of smoking and reactive inflammation?" Primary Care Respiratory Journal, vol. 17, no. 4, pp. 199-205, 2008. 


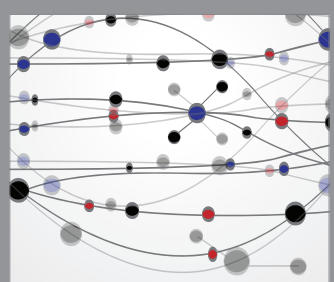

The Scientific World Journal
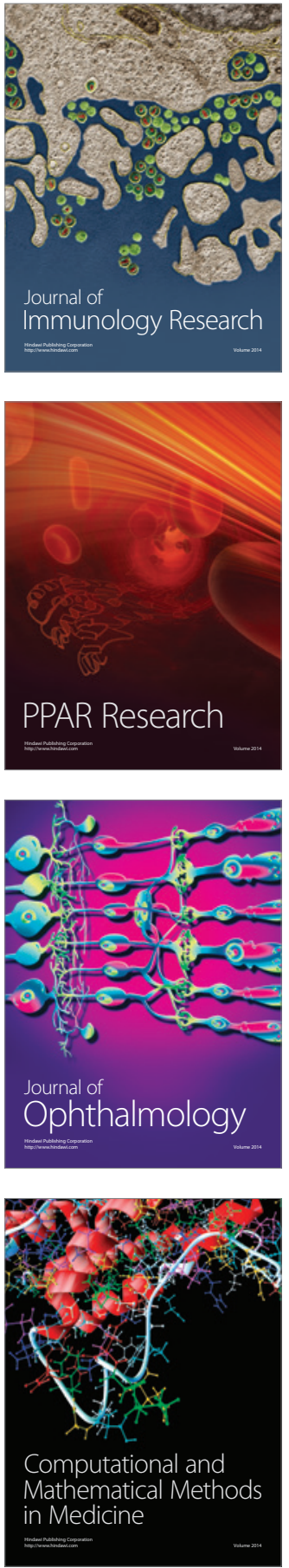

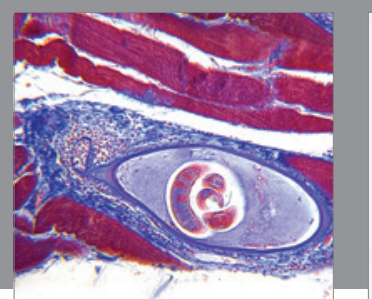

Gastroenterology Research and Practice

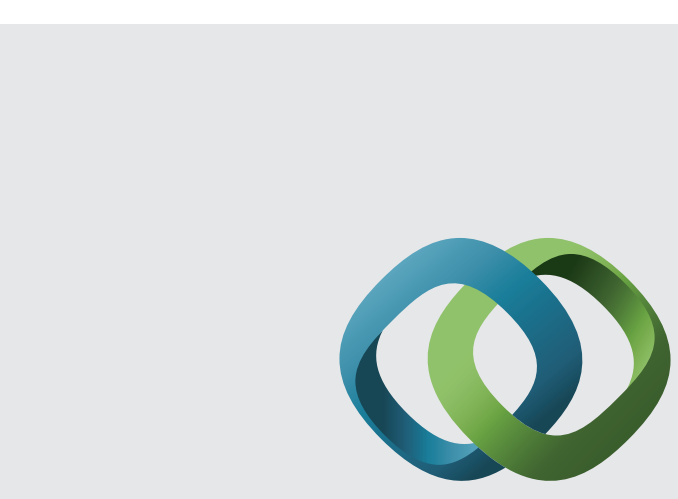

\section{Hindawi}

Submit your manuscripts at

http://www.hindawi.com
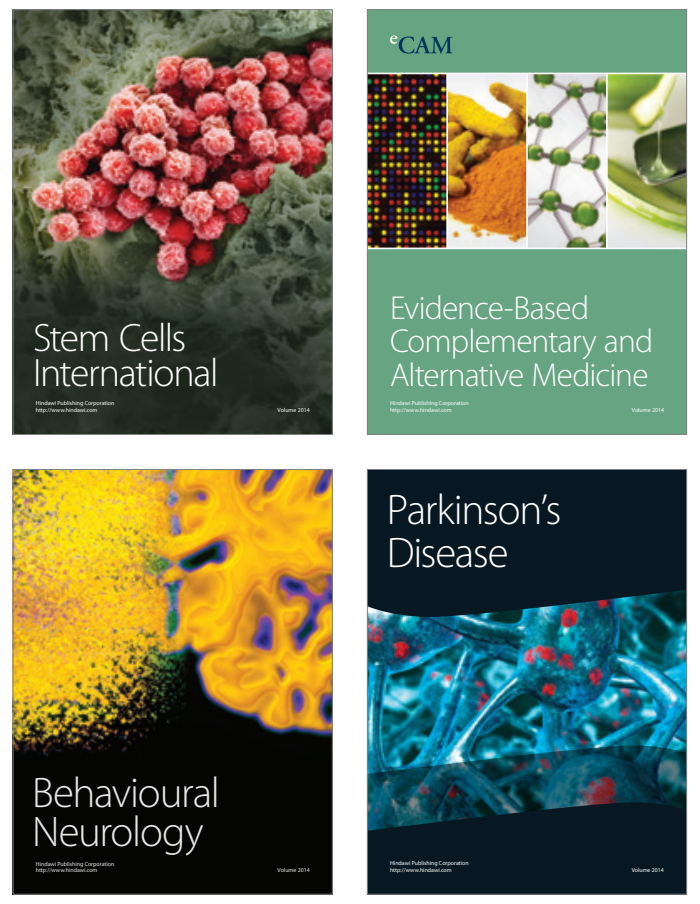
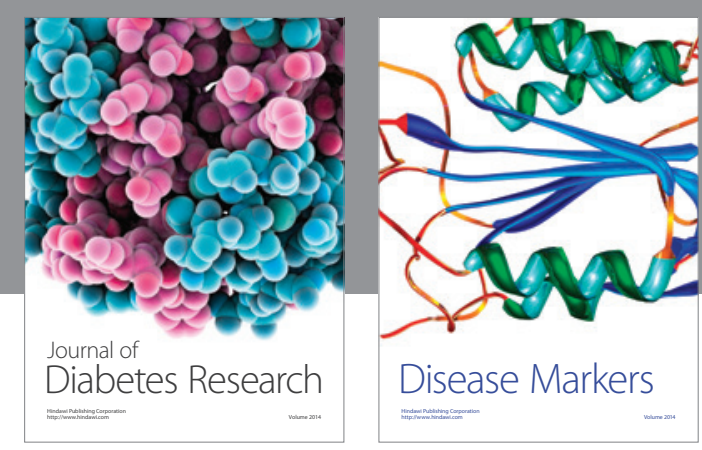

Disease Markers
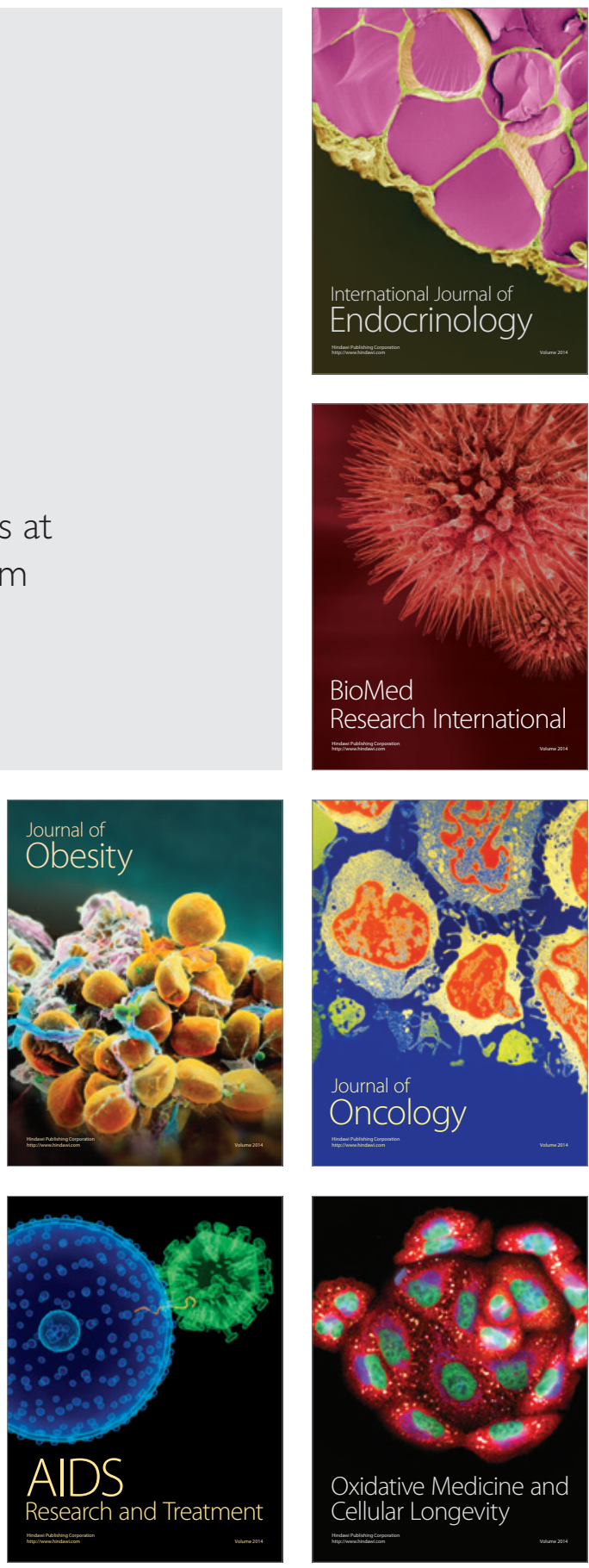